\title{
A TERTIARY CARE HOSPITAL-BASED RETROSPECTIVE STUDY EVALUATING AGE AND GENDER DIFFERENCES IN AUDIOLOGICAL FINDINGS
}

\author{
Ravi $D^{1}$, Hanumanth Prasad M², Lakshmi M. S3, Sahana P4 \\ ${ }^{1}$ Associate Professor, Department of ENT, Mandya Institute of Medical Sciences, Mandya. \\ 2 Professor and HOD, Department of ENT, Mandya Institute of Medical Sciences, Mandya. \\ ${ }^{3}$ Audiologist, Department of ENT, Mandya Institute of Medical Sciences, Mandya. \\ ${ }^{4}$ Audiologist, Department of ENT, Mandya Institute of Medical Sciences, Mandya.
}

\section{ABSTRACT}

\section{BACKGROUND}

Prevalence of hearing loss varies across studies owing to methodological differences and regional differences. In the light of newly launched and running hearing health care programs, there is a great need of region-specific prevalence estimation to support proper planning of these programs.

\section{MATERIALS AND METHODS}

Retrospective analysis of audiograms of individuals (1987), who visited Medical Teaching Institute of Mandya, was carried out for a period of eighteen months. Age wise and gender wise comparison of type and degree of hearing loss was carried out to analyze the effect of respective variables.

\section{RESULTS}

High occurrence of hearing loss was found in males, adult and older adult age groups. Sensorineural hearing loss and moderate degree of hearing loss had higher frequency compared to other types and degrees of hearing losses.

\section{CONCLUSION}

Observation of high prevalence of mild-to-moderate degree and sensorineural hearing loss necessitates organisation of appropriate and tailor-made awareness, early identification and rehabilitation programs to address specific target groups.

\section{KEYWORDS}

Retrospective Study, Age Differences, Gender Differences, Audiological Evaluation.

HOW TO CITE THIS ARTICLE: Ravi D, Prasad HM, Lakshmi MS, et al. A tertiary care hospital-based retrospective study evaluating age and gender differences in audiological findings. J. Evolution Med. Dent. Sci. 2017;6(21):1678-1682, D0I: $10.14260 /$ Jemds/2017/369

\section{BACKGROUND}

Hearing loss is the second leading disability and top most cause for the sensory deficit in the world.[1] It is considered as a hidden disability, which is difficult to identify. Hence, it is often neglected or late identified and rehabilitated. ${ }^{[2]}$ Hearing disability has a pervasive effect on a person's life affecting person's communication, vocational abilities, emotional and social wellbeing. ${ }^{[3,4,5]}$ It is observed as a global burden ${ }^{[6]}$ and it is considered best to prevent this problem from occurring or to identify it at the earliest to reduce the impact of the problem. In India national level programs, self-initiated small scale screening and evaluation camps by Government, nonGovernment and non-profit organisations are striving for early identification of hearing loss. They are also working towards spreading awareness regarding the causes of hearing loss, the impact of hearing loss among common people. In addition, many state and national programs are

Financial or Other, Competing Interest: None.

Submission 03-02-2017, Peer Review 28-02-2017,

Acceptance 06-03-2017, Published 13-03-2017.

Corresponding Author:

Lakshmi M. S

Audiologist,

Department of ENT,

Mandya Institute of Medical Sciences,

Mandya.

E-mail:lakshmims.yan@gmail.com

DOI: $10.14260 /$ jemds $/ 2017 / 369$ for these programs is the evidence-based information on nature of hearing loss (type and degree) and prevalence across gender and age groups. This information equips all those who are involved in these programs to select appropriate target group and to plan programs accordingly.

The prevalence studies conducted in the Indian context are either Institution based studies or Survey and/or Community level camp based studies. Institution based studies like study conducted by Devadiga et al (2013)[7] reports the prevalence of auditory disorders to be $62 \%$ (Among communication disorders) in Manipal, Karnataka. Hospital data based studies conducted by Balasubramanian et al (2015) ${ }^{[8]}$ at Tanjavur, Tamilnadu and Kanjikar et al (2015)[9] in Bidar, Karnataka have revealed a high prevalence of hearing loss in males compared to females. They also found the sensorineural hearing loss to be present more in elderly individuals and conductive hearing loss to be present more in younger individuals. A study conducted by Kulakarni et al (2014) ${ }^{[10]}$ in Nashik district, Maharashtra, revealed Chronic Suppurative Otitis Media (CSOM) to be highly prevalent in females.

Studies based on survey and community level camp also provides valuable facts regarding the prevalence of hearing impairment in rural regions. A study conducted by Sreeraj and Colleagues (2013)[11] in a rural region of Karnataka revealed the occurrence of hearing loss as $90.58 \%$. Another 
study from the same author ${ }^{[12]}$ reported the prevalence of ear related problems in few Islands of Lakshadweep to be $2.24 \%$. Study conducted by Sujeet Kumar and Colleagues ${ }^{[2]}$ in rural parts of Gujarat revealed prevalence rate of ear related problems to be $3.3 \%$. Study conducted by Saud et al (2014) ${ }^{[13]}$ in schools of Ghaziabad, Jammu and Kashmir revealed the incidence of hearing loss to be $9.3 \%$.

\section{Need for the Study}

The prevalence studies conducted vary in many aspects like the target group selected, region of study, methodology, classification method used for degree and type of hearing loss. Also, these studies report varied results when the prevalence of ear related problems, distribution of gender and degree of hearing loss are considered. Many studies reveal male preponderance in hearing loss prevalence[2,7,8,9,12]; however, a study conducted by Kulakarni et al (2014) ${ }^{[10]}$ in Nashik district, Maharashtra, revealed CSOM to be highly prevalent in females. The prevalence rate is also found to be different across regions (e.g. Islands of Lakshadweep - 2.24\%, rural region of Gujarat - 3.3\%; Karnataka (Manipal) hospital-based data: 62\%, rural region of Karnataka (Mandya) camp based data: 90.58\%). These differences are found even when the methodology is broadly similar[2,11,12] and the reason could be the resulting cultural and social differences among the study population. This finding emphasises the need for region specific studies to know the prevalence rate. In addition, Institution based studies have the advantage of a group of professionals attending patients and complete evaluation over surveybased studies. Though information obtained from Institutions do not represent the population as well as survey study, the accuracy of evaluation provides value to observations from these studies. Hence, there is a need for region specific Institution based studies to properly plan evaluation programs and rehabilitation programs at the community level and also at national level. The present study is thus planned to give facts on hearing loss nature and distribution in a tertiary level Health Care Centre in Mandya district. Also, an attempt is made to view the results in the background of currently running ear care programs.

\section{MATERIALS AND METHODS}

The study was conducted with the aim to describe the audiological findings in terms of degree and type of hearing loss in patients who reported to Medical Teaching Hospital, Mandya over a period of eighteen months. The effect of age and gender on the audiological profile was also examined. To accomplish the aim, the following procedure was followed.

\section{Source of Data}

The study followed retrospective design, where data collected from January 2015 to June 2016 was used. Approval from the Institutional Ethics Committee, Mandya Institute of Medical Sciences was obtained before initiation. A total of 1987 audiograms of the patients reported at Audiology section, ENT Department were analysed. The participants were in the age range of 3 to 90 years and were from in and around Mandya district. Patients with incomplete demographic details and audiometric results were excluded from the study.

\section{Procedure}

Pure-tone audiometry was performed in a sound-treated room using Global (Type 2) audiometer. For all the patients testing was conducted on a single day of their visit. Every patient who visited Audiology Unit, a brief case history was taken followed by estimation of air and bone conduction thresholds using the Hughson-Westlake procedure. Speech Reception Threshold and Speech Identification scores were also measured. Clark's classification system was used to classify the degree of hearing loss.[14] The types of hearing loss considered for analysis were conductive, sensorineural and mixed hearing loss. The four age groups considered for analysis were according to WHO classification (1982).[15] Demographic details such as age, gender, type and degree of hearing loss were retrieved from the audiogram copies. Age and gender-wise comparisons with the type of hearing loss and degree of hearing loss were then conducted.

\section{RESULTS}

The study was conducted to examine the distribution of hearing loss across different age groups and gender. To accomplish the objectives of the study a total of 1987 audiograms were reviewed for demographic details like age, gender and evaluation details like type and degree of hearing loss. The data consisted information regarding 1130 (56.87\%) males and 857 (43.13\%) females. Information concerning degree and type of hearing loss was constituted for number of ears. Among the total population reviewed, 2779 ears (69.93\%) found to have hearing loss, while other 1195 ears $(30.07 \%)$ had normal hearing; 95\% confidence interval was calculated for each observation over total population (3974 ears) and the results were as depicted in Table 1.

\begin{tabular}{|c|c|c|c|c|c|c|c|c|}
\hline \multirow{2}{*}{$\begin{array}{c}\text { Age/ } \\
\text { Degree }\end{array}$} & \multicolumn{2}{|c|}{1 - 14 years } & \multicolumn{2}{|c|}{15 - 44 years } & \multicolumn{2}{|c|}{45 - 64 years } & \multicolumn{2}{|c|}{$65+$ years } \\
\hline & $\mathbf{M}$ & $F$ & $\mathbf{M}$ & $\mathbf{F}$ & $\mathbf{M}$ & $\mathbf{F}$ & $\mathbf{M}$ & $\mathbf{F}$ \\
\hline Minimal & $8( \pm 0.14)$ & $18( \pm 0.21)$ & $155( \pm 0.6)$ & $110( \pm 0.51)$ & $102( \pm 0.49)$ & $70( \pm 0.41)$ & $39( \pm 0.31)$ & $25( \pm 0.25)$ \\
\hline Mild & $14( \pm 0.18)$ & $8( \pm 0.14)$ & $103( \pm 0.49)$ & $122( \pm 0.54)$ & $131( \pm 0.56)$ & $117( \pm 0.53)$ & $99( \pm 0.49)$ & $51( \pm 0.35)$ \\
\hline Moderate & $19( \pm 0.21)$ & $12( \pm 0.17)$ & $106( \pm 0.5)$ & $101( \pm 0.49)$ & $183( \pm 0.65)$ & $128( \pm 0.55)$ & $135( \pm 0.56)$ & $75( \pm 0.42)$ \\
\hline $\begin{array}{l}\text { Moderately } \\
\text { Severe }\end{array}$ & $9( \pm 0.15)$ & $16( \pm 0.2)$ & $59( \pm 0.38)$ & $62( \pm 0.39)$ & $56( \pm 0.37)$ & $67( \pm 0.4)$ & $76( \pm 0.42)$ & $41( \pm 0.31)$ \\
\hline Severe & $6( \pm 0.12)$ & $9( \pm 0.15)$ & $46( \pm 0.33)$ & $43( \pm 0.32)$ & $54( \pm 0.36)$ & $25( \pm 0.25)$ & $54( \pm 0.36)$ & $20( \pm 0.22)$ \\
\hline Profound & $11( \pm 0.16)$ & $9( \pm 0.15)$ & $45( \pm 0.33)$ & $27( \pm 0.26)$ & $45( \pm 0.33)$ & $20( \pm 0.22)$ & $31( \pm 0.27)$ & $17( \pm 0.2)$ \\
\hline
\end{tabular}

Table 1. Distribution of Hearing Loss across Different Age Group and Gender

${ }^{*} \mathrm{M}=$ Male, $\mathrm{F}=$ Female, $95 \%$ confidence intervals are given in parenthesis 
Distribution of type and degree of hearing loss across age and gender. In our study population, sensorineural type and moderate degree $(27.31 \%)$ of hearing loss were found to have higher prevalence compared to other types and degrees of hearing losses irrespective of age and gender. Furthermore, mild (23.21\%) and minimal (18.96\%) were the second and third highly observed severity of hearing loss. Followed by sensorineural hearing loss (53.98\%) mixed hearing loss $(24.83 \%)$ had a higher frequency of observation, while conductive hearing loss (21.19\%) being the least.

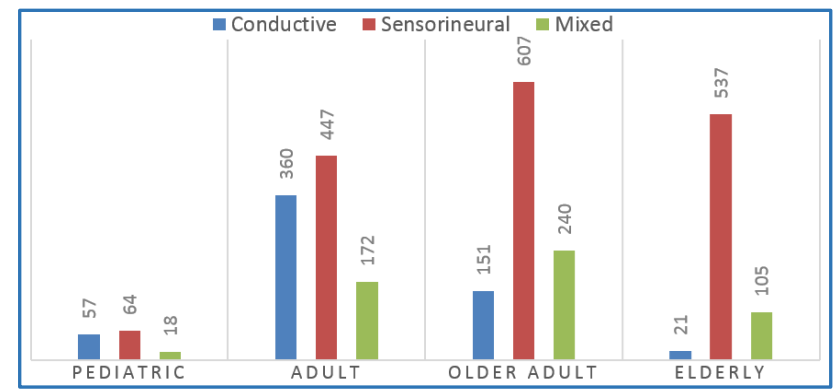

Figure 1. Distribution of Type of Hearing Loss across Age Groups Irrespective of Gender

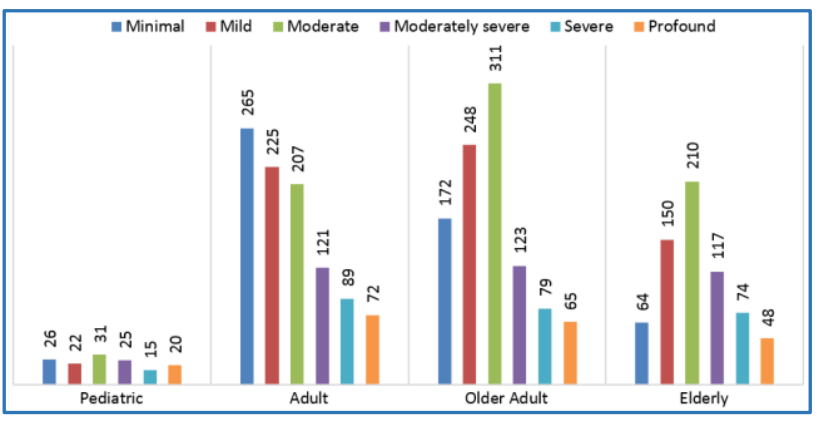

Figure 2. Distribution of Degree of Hearing Loss across Age Groups Irrespective of Gender

Of the total study population, paediatric age group constituted around 5\%, whereas adult group was $35.23 \%$, while the older adult group were $35.91 \%$ and finally geriatric population was $23.86 \%$. In paediatric ( 1 - 14 years) age group, sensorineural type and moderate hearing loss were highly prevalent followed by conductive and minimal degree of hearing loss. Similarly, the sensorineural hearing loss had the highest frequency of occurrence in the adult group followed by conductive hearing loss (15 - 44 years). However, minimal degree was observed to be more in this population in contrast to all other age groups. Furthermore, in both older adult ( 45 - 64 years) and geriatric age group, which followed the same trend of having a higher occurrence of moderate sensorineural hearing loss; mixed hearing loss found to have a second higher frequency of observation in contrast to paediatric population and adult group. In addition, the conductive and severe degree of hearing loss had the least prevalence in older adults and geriatric population (Figure 1 and 2). Across gender, comparison revealed a higher prevalence of conductive and mixed hearing loss in females and higher prevalence of sensorineural hearing loss in males.

\section{DISCUSSION}

The presence of hearing loss may have diverse effects depending on the age of onset. In paediatric population, presence of hearing loss increases the risk of speechlanguage, academic, psychosocial and emotional difficulties compared to normal peers. $[16,17,18,19,20]$ In the present study the paediatric population constituted $5 \%$ of the overall population, which found to have hearing loss. Among different type of hearing loss, moderate degree and sensorineural hearing loss had higher prevalence followed by minimal degree and conductive hearing loss. The results found were in contradiction with the studies conducted by Saud et al 2014[13] and Kalpana and Chamyal 1997.[21] A study conducted by Saud et al (2014) ${ }^{[13]}$ reported high prevalence of mild degree (34.41\%) and conductive hearing loss $(87.10 \%)$ in school going children in the age range of $6-12$ years $(\mathrm{N}=1000)$. Kalpana and Chamyal $(1997)^{[21]}$ also found Chronic Suppurative Otitis Media (CSOM) as the prime cause of hearing loss in school going children in the age range of 4 to 17 years $(\mathrm{N}=1200)$. Authors of these studies reported lower socio-economic state as one of the major cause of this observation. However, the present study reveals a high prevalence of sensorineural hearing loss and the possible reasons could be the population age range considered, regional differences and methodological difference. Also, children with CSOM may often report late to the district hospitals, as the symptoms are on and off in nature. Furthermore, the former studies[13,21] were conducted as part of the screening program, where self-report from children on signs and symptoms of conductive hearing loss were considered before evaluation. While in the present study, children's report may be preceded by the parental concern of hearing loss and thus leading to the higher observation of sensorineural hearing loss.

In the view of newly launching state-wise and nationwide (Like Pilot project, Karnataka, ADIP scheme to name a few) free cochlear implantation programs for children in low socio-economic status, also bearing in mind the adverse effect of hearing loss and high prevalence of moderate degree and sensorineural hearing loss in children in the present study authors recommend for long-term, stable free hearing aid distribution programs. Also, it should be noted that procurement and maintenance cost of the hearing aid can be less economically burdensome on program planners and on parents. Programs for early identification of conductive hearing loss in the form of school screening programs are also advocated as long-standing conductive hearing loss may lead to auditory deprivation. Fluctuating hearing loss due to repeated episodes of infection can also affect the academic performance of children. ${ }^{[22]}$ However, more Institution based long-term studies are warranted to confirm the present findings as the number of children reported are very less compared to the overall population reported.

In adults and elderly population, hearing loss may have an adverse effect on quality of life and overall functioning.[23,24] The present study revealed a higher prevalence of hearing loss in adults (35.23\%) and older adults (35.91\%) followed by elderly individuals (23.86\%). Sensorineural hearing loss was found to be more in older adults and elderly population compared to adults. The results of studies conducted by Kanjikar et al (2015) ${ }^{[9]}$ and Balasubramanian et al (2015),[8] are in agreement with the present study. The possible reasons for the present observation may be presbycusis witnessed in older individuals.[8,9] The second highest prevalent type of hearing 
loss in older adults and elderly individuals was mixed hearing loss. The probable reason for the same could be co-occurring stiffened tympanic membrane, impacted wax and presbycusis in older individuals. Another reason for the observation could be a long-standing conductive pathology. A study conducted by Kasliwal, Joshi and Pareek, (2004),[25] examined cooccurrence of sensorineural hearing loss and conductive pathology and reported a correlation between severity of sensorineural hearing loss and duration of conductive pathology and opine more severe conductive pathology as one of the reasons for the sensorineural hearing loss. Hence, screening programs and awareness programs for adults and elderly individuals, which focus on early detection and educating people on long-term effects of conductive hearing loss are suggested. High prevalence of conductive hearing loss in adult age group substantiates this recommendation.

Recruitment of professionals under National Program for Prevention and Control of Deafness in the state has increased access to evaluation facilities for hearing loss. However, there is a strong need for effective rehabilitation programs as high prevalence of mild-to-moderately severe degree of hearing loss is found in the present study and also by others. $[2,11,12]$ Study conducted by Sprinzl and Riechelmann (2010) [26] also report hearing aid as an effective method to treat mild-tomoderate hearing loss in elderly individuals. Nonetheless, despite the existing hearing aid distribution programs, lack of professionals, suitable infrastructure for distribution of hearing aids under Government schemes and lack of coordination among different bodies responsible for evaluation and distribution of hearing aids, there is a need to form a common body including representatives of all professionals who cater for persons with hearing loss to make currently existing programs effective. Also, the bodies which provide free hearing aids follow $40 \%$ or greater disability criteria for distribution of hearing aids, which is equivalent to moderateto-moderately severe degree of hearing loss. However, persons with mild-to-moderate hearing loss may also face significant communication difficulty. Hence, the authors suggest for extensive research in the direction of finding the prevalence of mild and moderate degree hearing loss and its effect on quality of life of individuals and efforts to revisit $40 \%$ criteria.

\section{CONCLUSION}

The present study documented the higher prevalence of moderate degree and sensorineural hearing loss in children and mild-to-moderate degree and sensorineural and mixed hearing loss in older adults and elderly population. Also, the high occurrence of conductive loss is noted in children and adults group. In view of these results, authors advocate for effective free hearing aid distribution programs and early identification programs aimed at conductive hearing loss for both children and adults.

\section{REFERENCES}

[1] Mathers C, Smith A, Concha M. Global burden of hearing loss in the year 2000. Global Burden of Disease 2000;18(4):1-30.

[2] Sinha SK, Shivaswamy J, Barman A, et al. Prevalence of communication disorders in a rural population at taluq level of Gujarat, India. Clinical Epidemiology and Global Health 2016.
[3] Yoshinaga-Itano C, Coulter D, Thomson V. The colorado newborn hearing screening project: effects on speech and language development for children with hearing loss. J Perinatol 2000;20(8 Pt 2):S132-7.

[4] Holm VA, Kunze LH. Effect of chronic otitis media on language and speech development. Pediatrics 1969;43(5):833-9.

[5] Glickman NS. Culturally affirmative mental health treatment for deaf people: what it looks like and why it is essential. In: Glickman NS, Gulati S, (eds.) Mental health care of deaf people 2003:1-32.

[6] Garg S, Chadha S, Malhotra S, et al. Deafness: burden, prevention and control in India. Natl Med J India 2009;22(2):79-81.

[7] Devadiga D, Varghese AL, Bhat J. Epidemiology of communication disorders and its role in rehabilitation. International Journal of Innovative Research and Development 2014;3(13).

[8] Balasubramanian GK, Thirunavukkarasu R, Kalyanasundaram RB, et al. Assessment of hearing status by pure tone audiogram-an institutional study. International Journal of Otolaryngology and Head \& Neck Surgery 2015;4(5):375-80.

[9] Kanjikar S, Doddamani A, Malige R, et al. Audiometric analysis of type and degree of hearing impairment and its demographic correlation: a retrospective study. Journal of Advanced Clinical \& Research Insights 2015;2:189-92.

[10] Kulkarni S, Burse KS, Patil D, et al. Retrospective study of clinical profile of patients with chronic suppurative otitis media at a tertiary health centre. MVP Journal of Medical Science 2014;1(1):7-12.

[11] Konadath S, Suma C, Jayaram G, et al. Prevalence of communication disorders in a rural population of republic of india. Journal of Hearing Science 2013;3(2):OA41-9.

[12] Konadath S, Chatni S, Lakshmi MS, et al. Prevalence of communication disorders in a group of islands in India. Clinical Epidemiology and Global Health 2016.

[13] Saud LC, Sajad H, Lateef I, et al. A prospective study of hearing impairment in school going children of Ghaziabad city attending a tertiary care hospital. Online J Otolaryngol 2014;4(4):28-41.

[14] Clark JG. Uses and abuses of hearing loss classification. ASHA 1981;23(7):493-500.

[15] World Health Organization. Provisional guidelines on standard international age classification. Department of International Economic and Social Affairs. Series M. 1982:No. (74).

[16] Davis JM, Elfenbein J, Schum R, et al. Effects of mild and moderate hearing impairments on language, educational, and psychosocial behavior of children. J Speech Hear Disord 1986;51(1):53-62.

[17] Crandell CC. Speech recognition in noise by children with minimal degrees of sensorineural hearing loss. Ear Hear 1993;14(3):210-6.

[18] Bess FH, Dodd-Murphy J, Parker RA. Children with minimal sensorineural hearing loss: prevalence, educational performance, and functional status. Ear Hear 1998;19(5):339-54. 
[19] Most T. The effects of degree and type of hearing loss on children's performance in class. Deafness \& Education International 2004;6(3):154-66.

[20] Daud MK, Noor RM, Rahman NA, et al. The effect of mild hearing loss on academic performance in primary school children. Int J Pediatric Otorhinolaryngol 2010;74(1):67-70.

[21] Kalpana R, Chamyal PC. Study of prevalence and aetiology of the hearing loss amongst school going children. Indian J Otolaryngol Head Neck Surg 1997;49(2):142-4.

[22] Friel-Patti S, Finitzo-Hieber T, Conti G, et al. Language delay in infants associated with middle ear disease and mild, fluctuating hearing impairment. Pediatr Infect Dis 1982;1(2):104-9.
[23] Laforge RG, Spector WD, Sternberg J. The relationship of vision and hearing impairment to one-year mortality and functional decline. J Aging Health 1992;4(1):126-48.

[24] Mulrow CD, Aguilar C, Endicott JE, et al. Association between hearing impairment and the quality of life of elderly individuals. J Am Geriatr Soc 1990;38(1):4550 .

[25] Kasliwal N, Joshi S, Pareek SM. Determinants of sensorineural hearing loss in chronic middle-ear disease. Indian J Otolaryngol Head Neck Surg 2004;56(4):269-73.

[26] Sprinzl GM, Riechelmann H. Current trends in treating hearing loss in elderly people: a review of the technology and treatment options-a mini-review. Gerontology 2010;56(3):351-8. 